\title{
TRANSPORT IN POROUS AND FRACTURED MEDIA OF THE CREEDE FORMATION
}

\author{
James L. Conca \\ Washington State University Tri-Cities \\ Environmental Sciences \\ 100 Sprout Road \\ Richland, Washington 99352
}

\begin{abstract}
Direct measurement was made of the hydraulic conductivity of Creede Formation rocks using a new experimental method. The UFA ${ }^{\mathrm{TM}}$ method employs open-flow centrifugation.
\end{abstract} Centrifugation, like gravity, has the effect on a material of a whole-body force exerting equal force at all points within the sample. The equivalent gravitational force exerted throughout the sample can be chosen to be from one to four orders of magnitude higher than earth gravity (from 10 to $10,000 \mathrm{~g}$ ). The result is an increase in rate of fluid flow equally at all points throughout the sample so that hydraulic steady state is obtained in most geologic materials in hours, even under highly unsaturated conditions. This extraordinarily short time allows direct measurement of transport parameters, such as hydraulic conductivity, diffusion coefficient, and retardation factors, in any porous media over the complete range of field moisture contents. Traditional techniques and estimation methods require months to years to obtain these data, and cannot provide data for samples at low water contents. Hydraulic conductivities in the Creede Formation rocks ranged from $10^{-12} \mathrm{~cm} / \mathrm{s}$ to $10^{-7} \mathrm{~cm} / \mathrm{s}\left(10^{-9}\right.$ Darcy to $10^{-4}$ Darcy) and showed no correlation with any other physical or mineralogical properties including porosity. The high degree of alteration to clay minerals appears to obscure any porosity/permeability relationship of the kind that occurs in many reservoir rocks. However, down-hole neutron porosities correlated well with laboratorydetermined porosities.

This report was prepared as an account of work sponsored by an agency of the United States Government. Neither the United States Government nor any agency thereof, nor any of their employees, makes any warranty, express or implied, or assumes any legal liability or responsibility for the accuracy, completeness, or usefulness of any information, apparatus, product, or process disclosed, or represents that its use would not infringe privately owned rights. Reference herein to any specific commercial product, process, or service by trade name, trademark, manufacturer, or otherwise does not necessarily constitute or imply its endorsement, recommendation, or favoring by the United States Government or any agency thereof. The views and opinions of authors expressed herein do not necessarily state or reflect those of the United States Government or any agency thereof. 


\section{DISCLAIMER}

Portions of this document may be illegible in electronic image products. Images are produced from the best available original document. 


\section{INTRODUCTION}

The objective of this investigation is to determine the hydrologic transport parameters of Creede formation rocks for use in transport model development and for image analysis of transport pathways to produce a porosity/permeability evolution curve in support of geochemical and isotopic water/rock interaction models. This project directly measures the hydraulic conductivity, the diffusion coefficient and the actual fluid flow paths in rocks of the Creede Formation using recently developed open-flow centrifugation techniques (the UFA ${ }^{\mathrm{TM}}$ ). Samples are being investigated from the two deep drill holes into altered and unaltered Creede formation rocks from each of the units of interest, i.e., tuffs, volcanoclastics, megabreccias and other collapse-derived units. Twenty samples have been run to date with twenty more anticipated by the middle of 1994 .

\section{METHODOLOGY}

Transport parameters have traditionally been difficult to measure in fractured and porous media, and have generally been inferred from porosity information. The newly-developed flow apparatus, the UFA, based on open-flow centrifugation, can directly determine hydraulic conductivity. In the UFA hydraulic steady-state can be achieved in a matter of hours to days in fractured and porous geologic materials (Conca and Wright, 1992). There are specific advantages to using a centripetal acceleration as a fluid driving force. It is a whole-body force similar to gravity, and so acts simultaneously over the entire system and independently of other driving forces, e.g., gravity or matric suction. There is no compaction, dewatering of clays, or induced fracturing that usually occur with high-pressure techniques in these materials because high point pressures are not generated in the UFA. The UFA consists of a rock core ultracentrifuge with a constant, ultralow flow-rate pump which will provide the Creede groundwater (or any fluid) to the sample through a rotating seal assembly and microdispersal system (Figure 1). Accelerations up to $20,000 \mathrm{~g}$ are attainable at temperatures from $-20^{\circ}$ to $150^{\circ} \mathrm{C}$ and flow rates as low as $0.001 \mathrm{ml} / \mathrm{hr}$. The effluent is collected in a transparent, volumetrically-calibrated container at the bottom of the sample assembly which is observed during centrifugation using a strobe light. 
Under a centripetal acceleration in which the water is driven by the centrifugal force per unit volume, $\rho \omega^{2} r$, Darcy's Law is given by

$$
q=-K\left[-\rho \omega^{2} r\right]
$$

where $q$ is the flux density into the sample; $K$ is the hydraulic conductivity, $r$ is the radius from the axis of rotation; $\rho$ is the fluid density; and $\omega$ is the rotation speed. Diffusion coefficients can be determined using the Nernst-Einstein/electrical conductivity relationship recently developed to describe aqueous diffusion in geologic systems and uses an electrical conductivity cell as the sample holder in the UFA. Dyed groundwater can be used to trace the actual flow paths after drying and thin-sectioning. These sections can then be investigated using image analysis techniques.

\section{COMPARISON OF UFA METHOD WITH TRADITIONAL TECHNIQUES}

Several studies were made to compare the UFA method with other experimental and estimation methods for determining hydraulic conductivity. Figure 2 is a comparison of the UFA method to three other techniques for determining the hydraulic conductivity as a function of volumetric water content, $\theta$, for soils from the Hanford Site Buried Waste Test Facility (BWTF). The hydraulic conductivity as a function of volumetric water content is also known as the characteristic curve, $\mathrm{K}(\theta)$. The BWTF samples consist of Hanford Formation sediments that are coarse to mediumgrained fluvio-glacial soils with a dominantly volcanic source lithology. These sediments are composed of approximately 85 to $90 \%$ sand, 5 to $10 \%$ silt, and 3 to $6 \%$ clay-size particles by weight. In Figure 2, open squares are direct measurements of $K(\theta)$ using the UFA method. All of the UFA measurements over the full range of volumetric water contents were conducted in only 3 days. Open triangles are direct measurements of $\mathrm{K}(\theta)$ using traditional column flow experiments under unit-gradient conditions, requiring approximately a year of experimental time to obtain hydraulic steady states for this range of water contents (Michael Fayer, personal communication). An estimation of hydraulic conductivity of the BWTF soils was derived by using the Campbell 
relationship to fit laboratory-determined water retention values to matric potential values in order to generate the Mualem relationship shown by the solid line (van Genuchten, et al., 1992). Also shown in Figure 2 is a solid circle which represents the average of dozens of measurements taken regularly over 13 years from a field lysimeter under unit-gradient conditions at field water contents (Glendon Gee, personal communication). This data point ties the laboratory data to actual field conditions. The agreement of the UFA data with all three methods is excellent and demonstrates not only the feasibility but also the time saved by using the UFA method.

Several issues involving flow in an acceleration field are frequently raised and have been successfully addressed by previous and on-going research (Conca and Wright, 1992; Nimmo, et al., 1988). These studies have shown the following: 1) Compaction from acceleration is negligible in aggregate samples over $1.0 \mathrm{~g} / \mathrm{cm}^{3}$. Bulk densities in all samples have remained constant because a whole-body acceleration does not produce high point pressures. Properties of fractured rock are completely unaffected by the acceleration field. 2) Three dimensional deviations of the driving force with position in the sample are less than $1 \% .3$ ) Moisture distribution is uniform to within $3 \%$ in homogeneous systems because water content depends only upon $\psi$, and unit gradient conditions are achieved in which $d \psi / d r=0$. In heterogeneous samples or multicomponent systems, each component reaches its own hydraulic conductivity and water content at steady state, as occurs under natural conditions in the field. This last effect cannot be reproduced with pressuredriven techniques, but only under a whole-body acceleration field.

\section{RESULTS}

Twenty plugged cores, seventeen from CCM-1 and three from CCM-2, have been run in the UFA to determine hydraulic conductivity. The data are given in Table 1. Figure 3 shows the porosity as a function of the permeability (given as the hydraulic conductivity, $\mathrm{K}$ ). There is no discernable relationship between porosity and permeability in these samples. This has been observed in other materials where significant clay minerals occur (Conca and Wright, 1992). The six samples from 
$1129.6^{\prime}$ to $1150.8^{\prime}$ correspond to a peculiar anomaly in the resistivity log over that depth range which goes through a continuous and almost constant increase. Therefore, the permeability was plotted against resistivity for all samples and is shown in Figure 4. Again, there is no correlation. Figures 5 and 6 show the permeability plotted against magnetic susceptibility and depth, illustrating that no correlations exists. Geophysical data was provided by Dr. Philip Nelson of the United States Geological Survey (see accompanying paper this volume).

The hydraulic conductivity results show that clay alteration products dominate the present permeability characteristics of the Creede Formation, making the samples less permeable than anticipated. The $1304.9^{\prime}$ and the $1306.9^{\prime}$ samples are two petrologically similar samples on either side of a major alteration zone that visually left the 1306.9' sample pink and obviously altered. While the alteration dramatically increased the porosity from less than $20 \%$ to over $40 \%$, the permeability increased by only a factor of four, a very small difference. Even more problematic are two samples, at $1141.5^{\prime}$ and $1144.5^{\prime}$, that have extremely different permeabilities, $4.8 \times 10^{-12}$ $\mathrm{cm} / \mathrm{s}$ and $3.9 \times 10^{-8} \mathrm{~cm} / \mathrm{s}$, respectively, but are identical in every other way: mineralogically, physically, color, density, porosity, alteration mineralogy, in hand specimen and in thin section. The only difference observed between the two specimens was under the scanning electron microscope, where dissolved glass shards in the sample from $1144.5^{\prime}$ formed slightly larger pores, the authigenic minerals were more euhedral and the smectite minerals had not grown across the pore spaces as much as in the sample from 1141.5' (Figures 7 and 8). This is a seemingly minor effect that would ordinarily escape notice, but it apparently has severely effected the permeability and probably resulted from a slight difference in alteration history involving fluid migration rates and/or local aqueous chemistry. This indicates that generalizations based on bulk rock properties will sometimes be misleading. Dr. Laura Crossey performed the SEM work at the University of New Mexico.

Another important result has been the observation that the borehole neutron porosity determinations 
matched the laboratory-determined saturated porosity measurements very well (Figure 9). Differences may result from the inclusion of structural water in the neutron measurement that does not reflect actual porosity and/or incomplete drying, or the loss of structural water during drying, in the laboratory.

\section{CONCLUSION}

Hydraulic conductivities in cores from the Creede Formation investigated in this study ranged from $10^{-12} \mathrm{~cm} / \mathrm{s}$ to $10^{-7} \mathrm{~cm} / \mathrm{s}$. These results for the first twenty cores run on the Creede Formation rocks from the Creede moat drill holes illustrate that there is no correlation between permeability and any other physical or mineralogical property including porosity, petrology, alteration mineralogy, resistivity, magnetic susceptibility, density or depth. The permeability is a function of each samples unique geologic and alteration history and broad generalizations concerning permeability will be non-defensible.

Acknowledgements - I would like to thank Laura Crossey and Phil Nelson for providing data and insightful discussions. This work was funded by the Geosciences Research Program through the Office of Basic Energy Sciences of the United States Department of Energy.

\section{REFERENCES}

CONCA, J. L., AND J. V. WRIGHT, "Diffusion and Flow in Gravel, Soil, and Whole Rock," Applied Hydrogeology, Volume 1 (1992).

NIMMO, J. R. AND K. C. AKSTIN, "Hydraulic conductivity of a sandy soil at low water content after compaction by various methods," Soil Science Society of America Journal, Volume 52 (1988).

VAN GENUCHTEN, M. TH., F.J. LEIJ, and L.J. LUND, "Indirect Methods for Estimating the Hydraulic Properties of Unsaturated Soils," Proceedings of the International Workshop on Indirect Methods for Estimating the Hydraulic Properties of Unsaturated Soils, University of California, Riverside (1992). 


\begin{tabular}{|c|c|c|c|c|c|c|}
\hline Creede Sample & Depth (ft) & $\mathrm{K}(\mathrm{cm} / \mathrm{s})$ & Lab Poros. (\%) & Neutron Poros. (\%) & Mag. Susc. (SI units) & Resistivity lohr \\
\hline 1R66-A4.15 & -585.650 & $1.12 \theta-7$ & 33.1 & . 34.9 & 14.369 & 35.366 \\
\hline 1R127-A8.05 & -1129.600 & $1.14 \theta-8$ & 29.1 & 31.4 & 15.016 & 6.104 \\
\hline 1R128-A4.2 & -1134.700 & $8.04 e-12$ & 29.2 & 33.3 & 563.070 & 5.528 \\
\hline $1 \mathrm{R} 129-\mathrm{A} 1.0$ & -1141.500 & $4.83 \theta-12$ & 20.4 & 25.1 & 944.820 & 16.213 \\
\hline $1 R 129-A 4.0$ & -1144.500 & $3.86 \theta-8$ & 23.6 & 23.3 & 982.730 & 22.803 \\
\hline $1 R 129-A 7.6$ & -1148.100 & $9.36 \theta-9$ & 14.5 & 23.2 & 351.140 & 28.597 \\
\hline $1 R 130-A 0.3$ & -1150.800 & $2.25 \theta-10$ & 26.8 & 31.8 & 224.250 & 11.698 \\
\hline $1 R 145-A 4.4$ & -1304.900 & $1.29 \theta-8$ & 22.3 & 17.3 & 1247.400 & 97.097 \\
\hline $1 \mathrm{R} 145-\mathrm{A} 6.4$ & -1306.900 & $5.37 \theta-8$ & 43.4 & 44.6 & 348.820 & 29.312 \\
\hline $2 \mathrm{R} 159-\mathrm{A} 1.5$ & -1601.500 & $1.23 \theta-8$ & 35.8 & 37.1 & 82.214 & 8.133 \\
\hline $2 \mathrm{R} 102-5.1 \mathrm{~V}$ & -1056.600 & $1.23 \theta-9$ & 21.7 & & & \\
\hline $2 \mathrm{R} 102-5.2 \mathrm{~h}$ & -1056.700 & $3.13 \theta-9$ & 26.6 & & & \\
\hline $1 R 131-A 0.55$ & -1159.100 & $5.900-10$ & 30.4 & 34.0 & 88.858 & 4.053 \\
\hline 1R131-A10.3 & -1168.800 & $4.79 e-10$ & 27.2 & 31.0 & 587.810 & 5.932 \\
\hline 1R132-A9.6 & -1178.100 & $7.040 \cdot 10$ & & 31.7 & 966.880 & 10.419 \\
\hline 1R134-A5.3 & .1193 .800 & $4.87 e-10$ & 23.7 & 32.8 & 1374.500 & 9.431 \\
\hline $1 R 135-A 3.8$ & -1202.800 & $1.23 \theta-9$ & 22.8 & 31.9 & 1475.700 & 18.438 \\
\hline 1R135-A6.7 & -1205.700 & $3.43 e-10$ & 6.8 & 9.5 & 461.840 & 77.057 \\
\hline $1 R 136-A 4.7$ & -1214.200 & $1.48 \theta-9$ & & 5.4 & 562.390 & 282.750 \\
\hline $9 \quad 1 R 137-A 4.55$ & -1224.100 & $1.37 \theta-9$ & 10.2 & 10.8 & 466.150 & 283.990 \\
\hline
\end{tabular}




\section{FIGURE CAPTIONS}

Figure 1 . The UFA ${ }^{\mathrm{TM}}$ rotor and seal assembly.

Figure 2. Characteristic curves for soil from the Buried Waste Test Facility using four methods.

Figure 3. Neutron porosity versus permeability, given as hydraulic conductivity, for samples of the Creede Formation, showing no apparent relationship. Designation and depth are shown for each sample. $(\mathrm{cm} / \mathrm{s}=1033$ Darcy)

Figure 4. Resistivity versus permeability, given as hydraulic conductivity, for samples of the Creede Formation, showing no apparent relationship.

Figure 5. Magnetic susceptibility versus permeability, given as hydraulic conductivity, for samples of the Creede Formation, showing no apparent relationship.

Figure 6. Depth versus permeability, given as hydraulic conductivity, for samples of the Creede Formation, showing no apparent relationship.

Figure 7. Scanning electron micrograph of the sample at $1144.5 \mathrm{ft}$. from the Fallout A unit showing porosity formed from dissolution followed by authigenic mineral formation. Electron micrograph by Laura Crossey.

Figure 8. Scanning electron micrograph of the sample at $1141.5 \mathrm{ft}$. from the Fallout $A$ unit showing porosity formed from dissolution followed by authigenic mineral formation. Note the difference in morphology compared to the previous figure and the pore-spanning authigenic minerals. Both samples are identical in hand specimen, density, porosity, color and mineralogy, but differ in their permeabilities by about four orders of magnitude. Electron micrograph by Laura Crossey.

Figure 9. Neutron porosity versus porosity determined in the laboratory by saturating with groundwater for two months. The agreement is very good considering the amount of structural water contained in the minerals of these altered volcanics which can contribute to errors in both methods. 


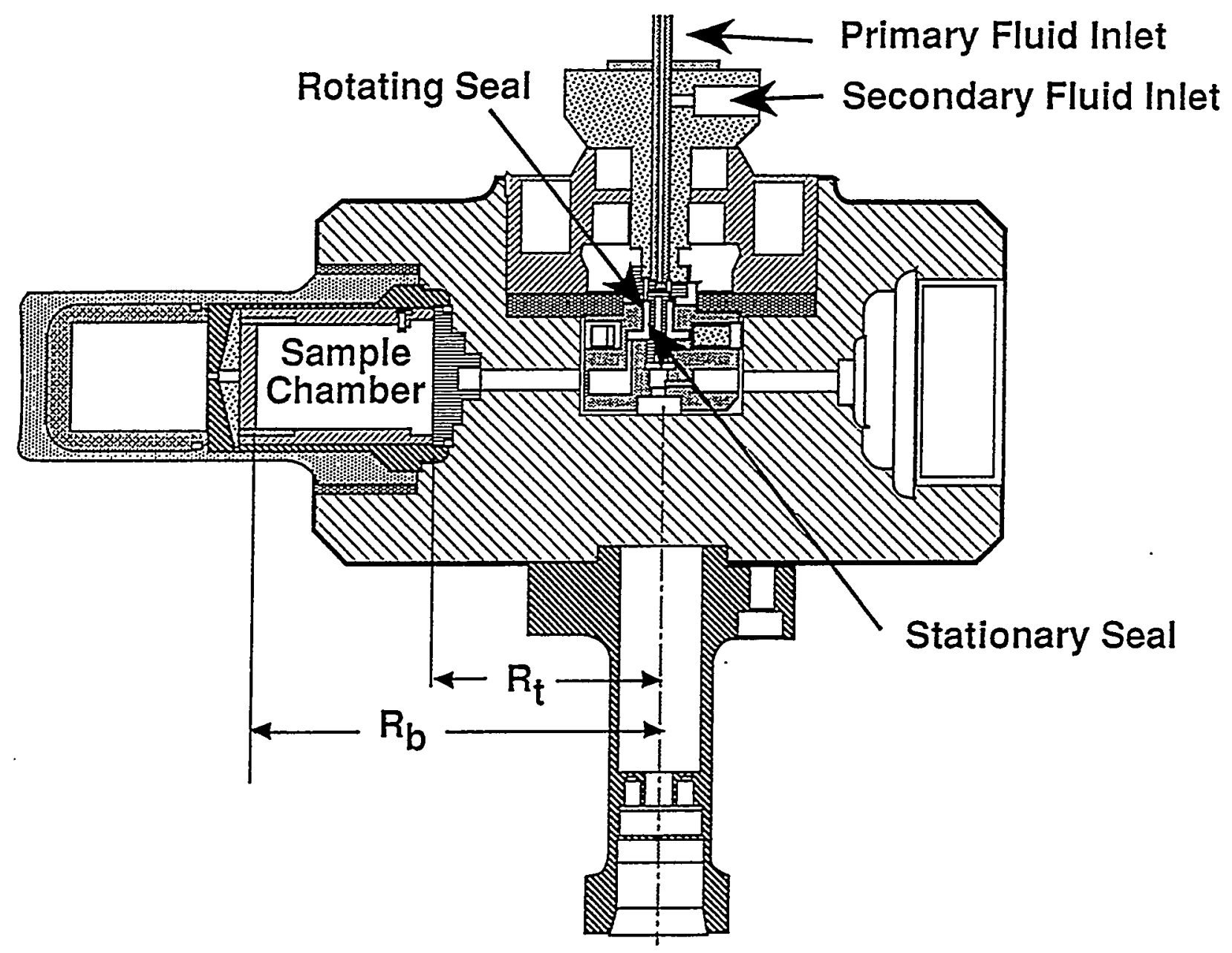




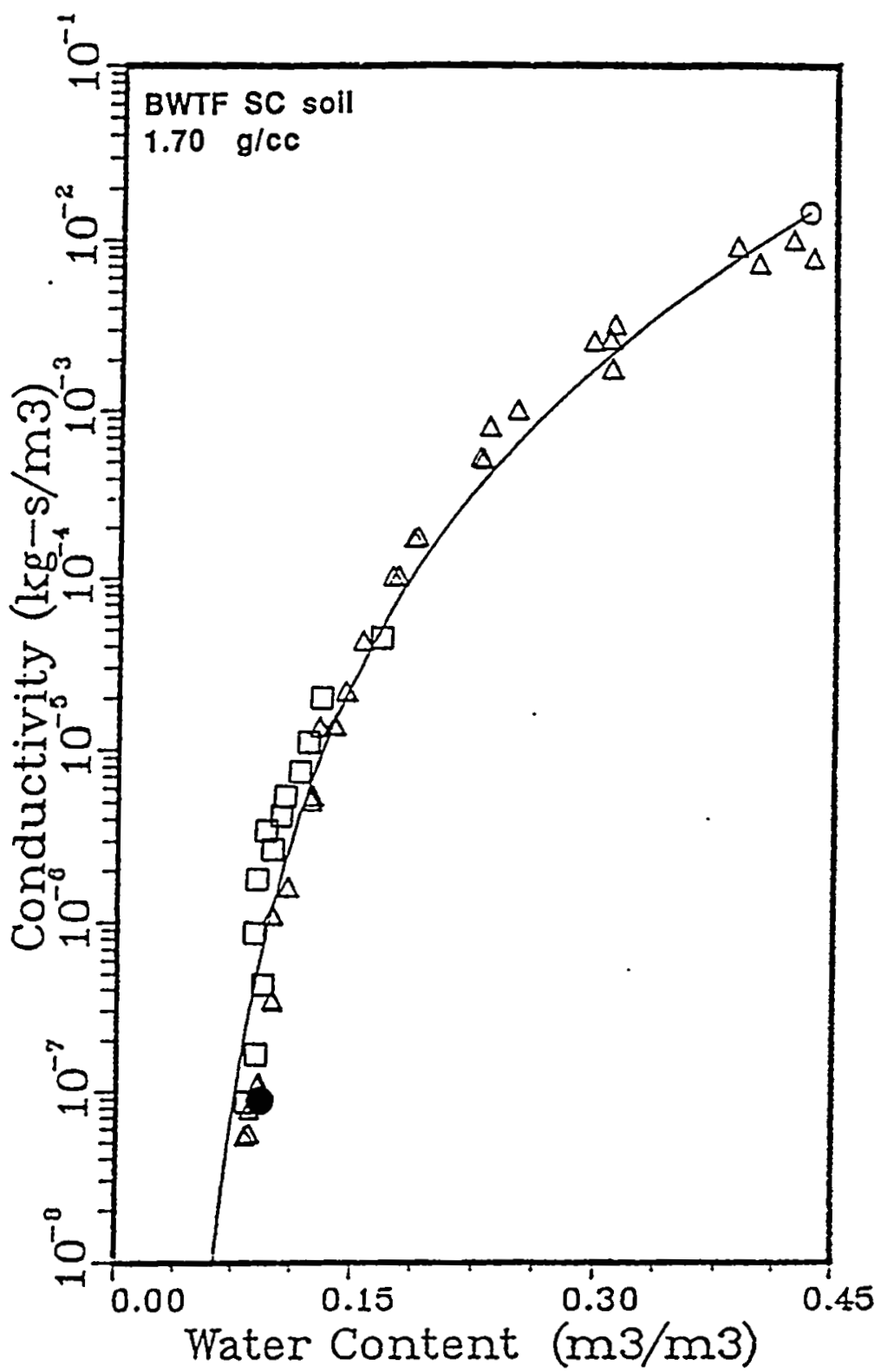

$\square \quad$ UFA $^{\text {TM }}$ measurements made over 3 -days

$\Delta$ Traditional column experiments made over 1-year

- Average of field lysimeter measurements made over 13-years

- Mualem estimation derived from curve-fitted water-retention data made over 6 -weeks 


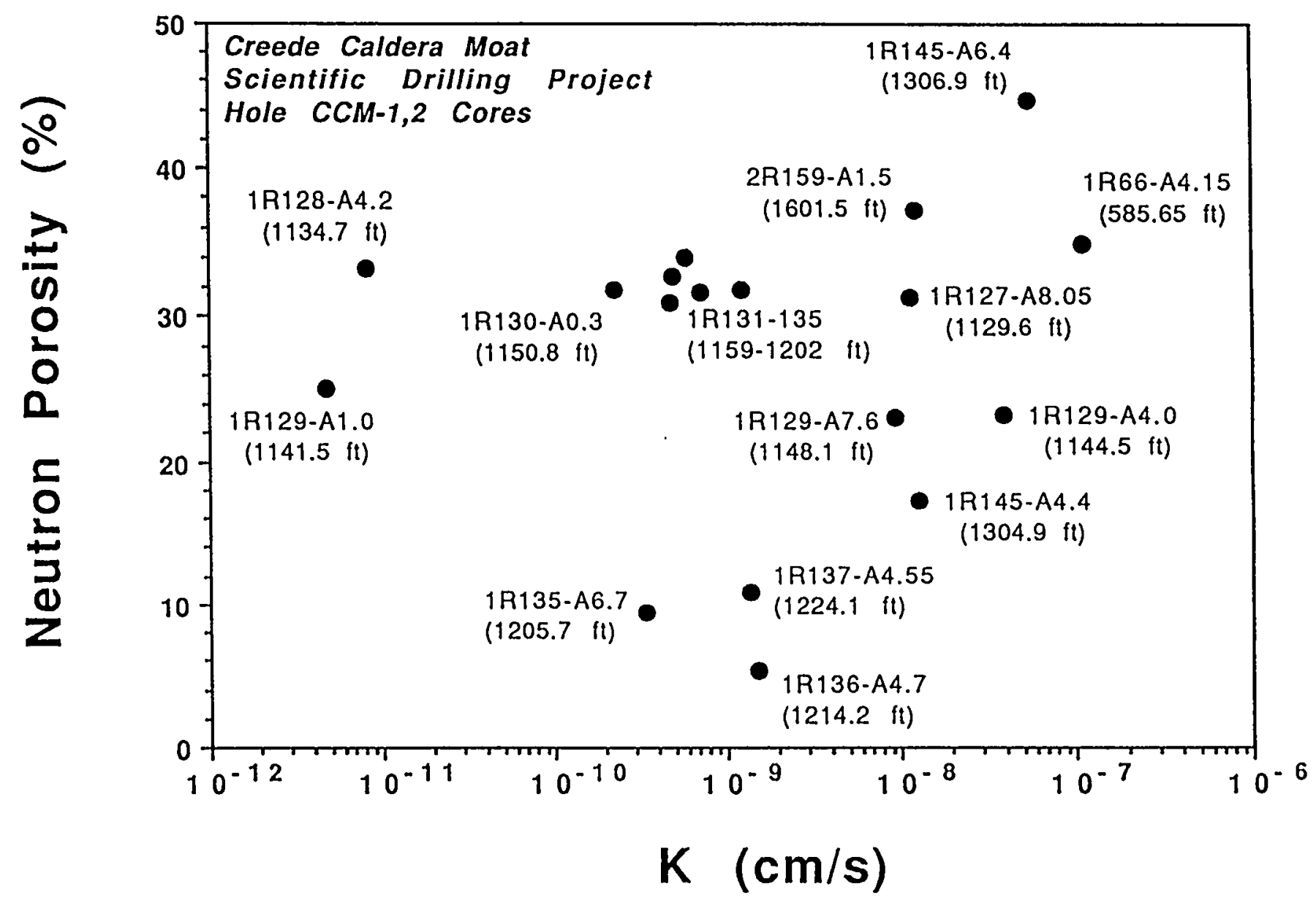




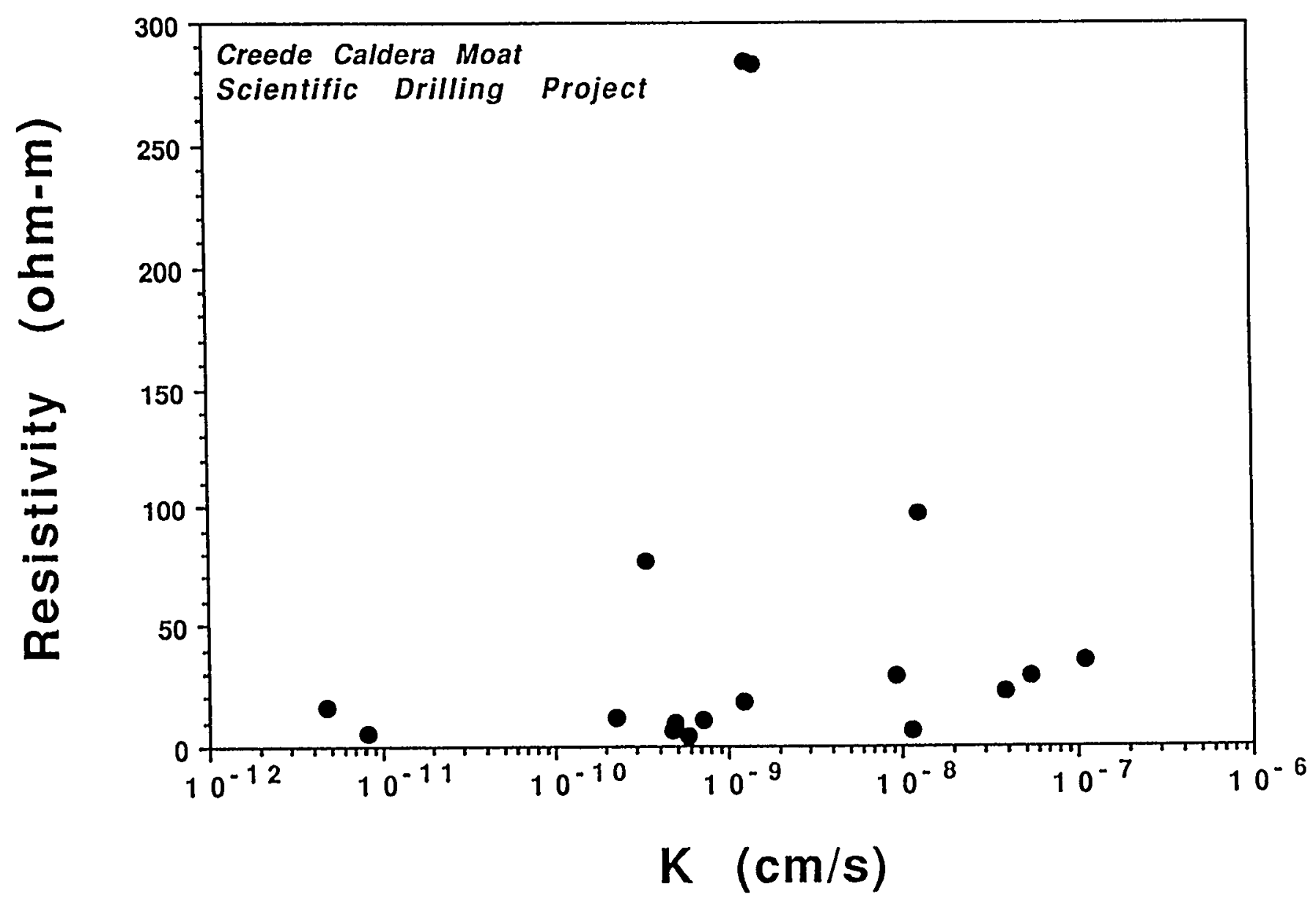




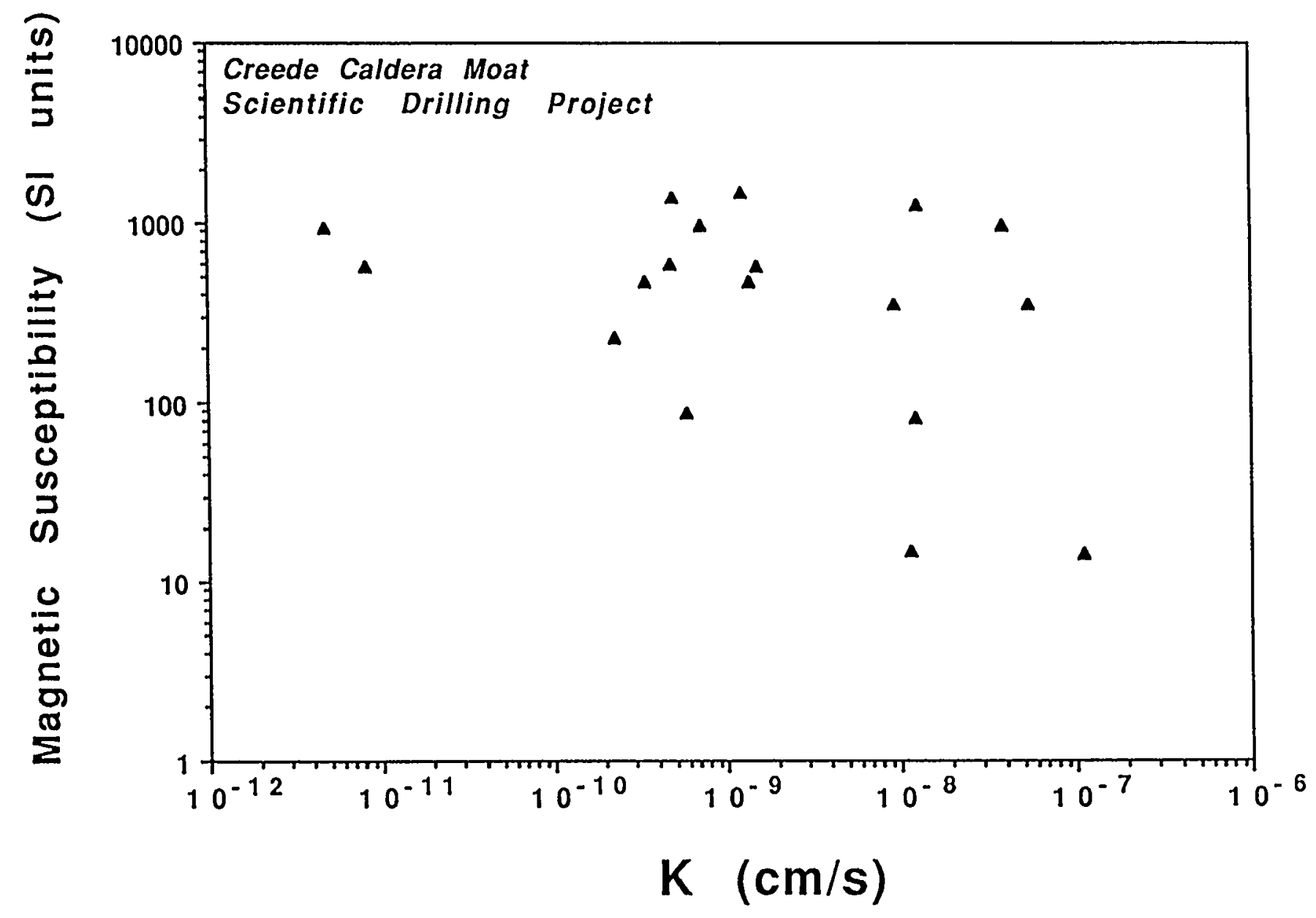




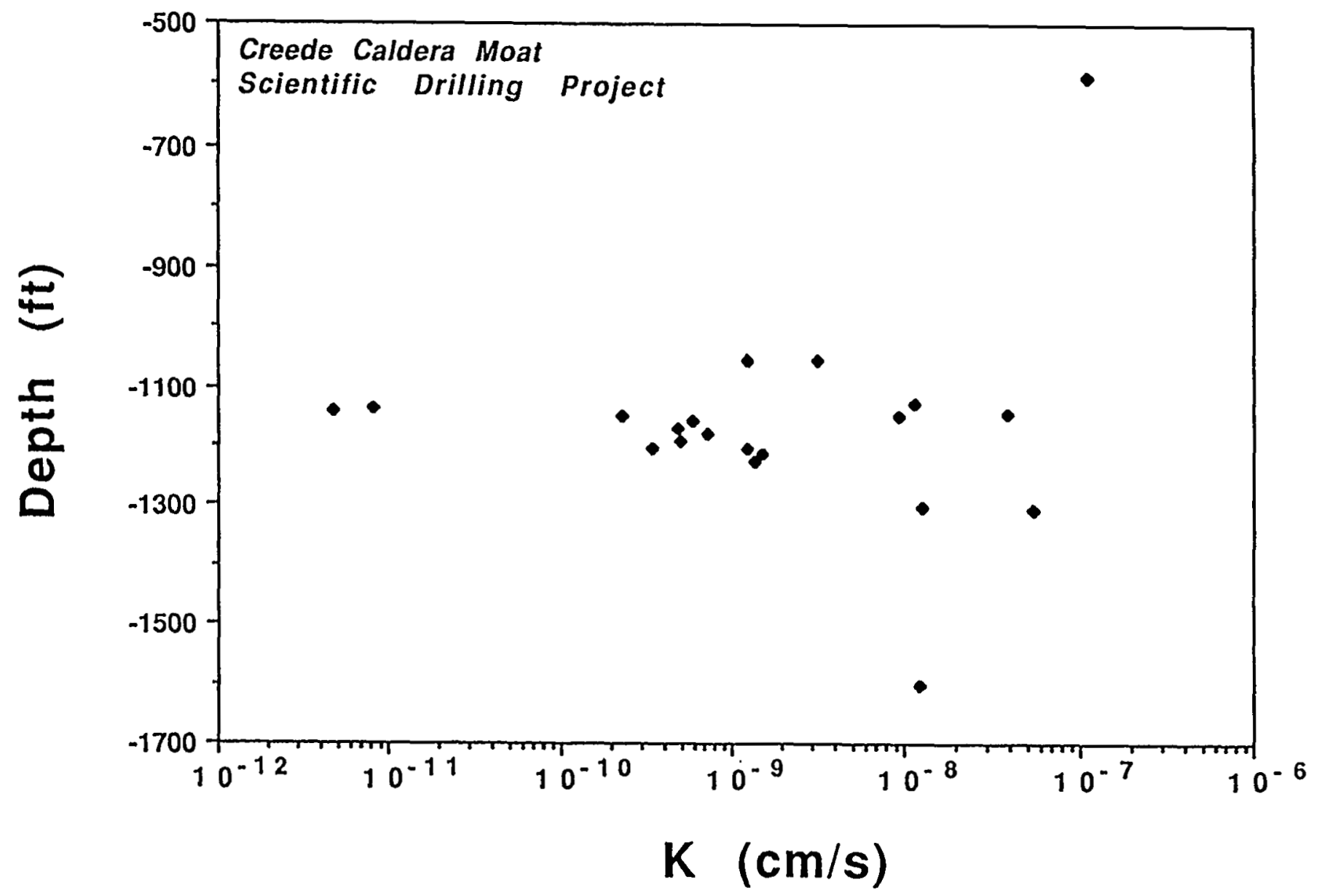




\section{CCM-1 $1144.5 \mathrm{ft} \quad K=1.2 \times 10^{-8} \mathrm{~cm} / \mathrm{s}$}

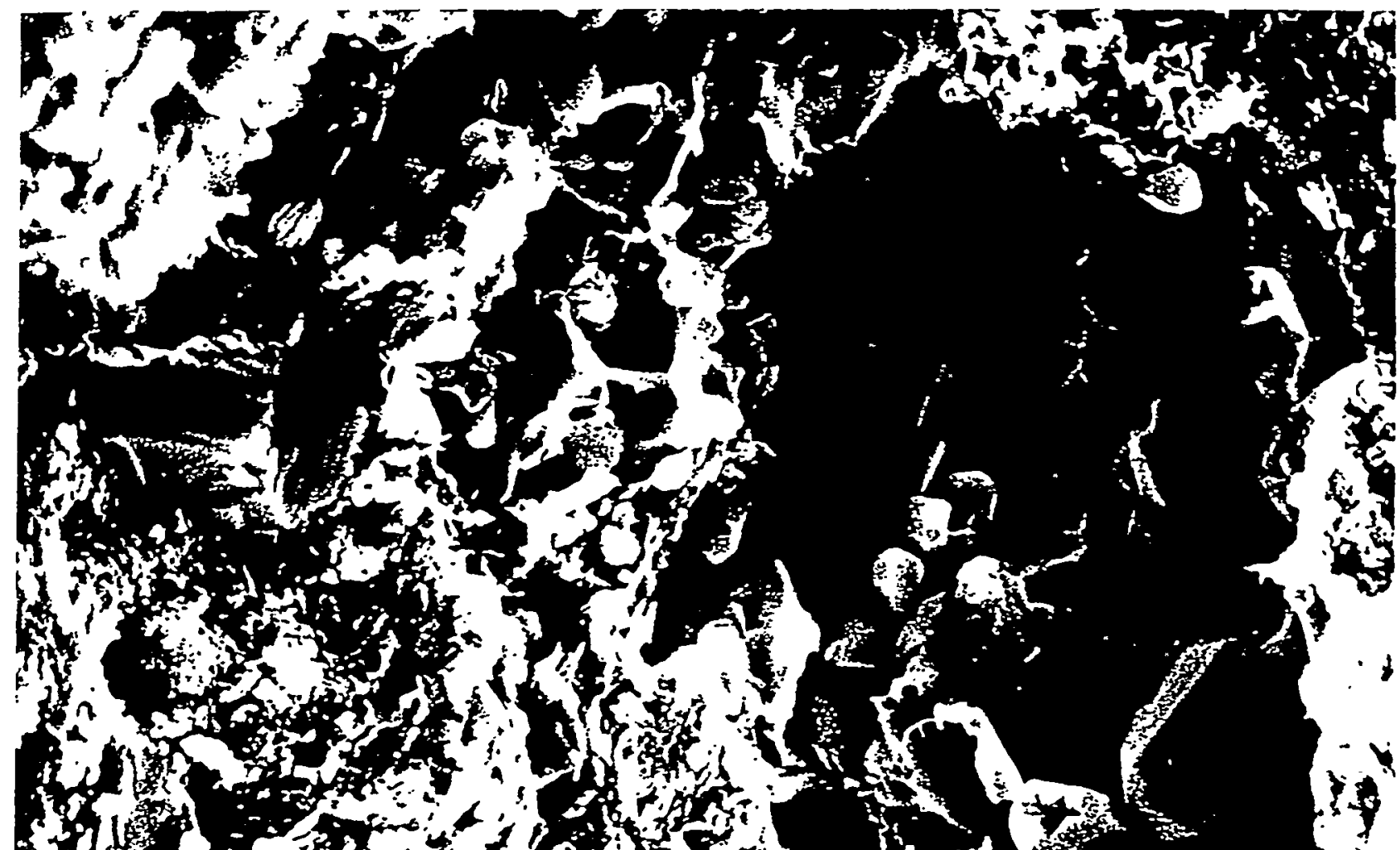

1.

$48+37$. (r)

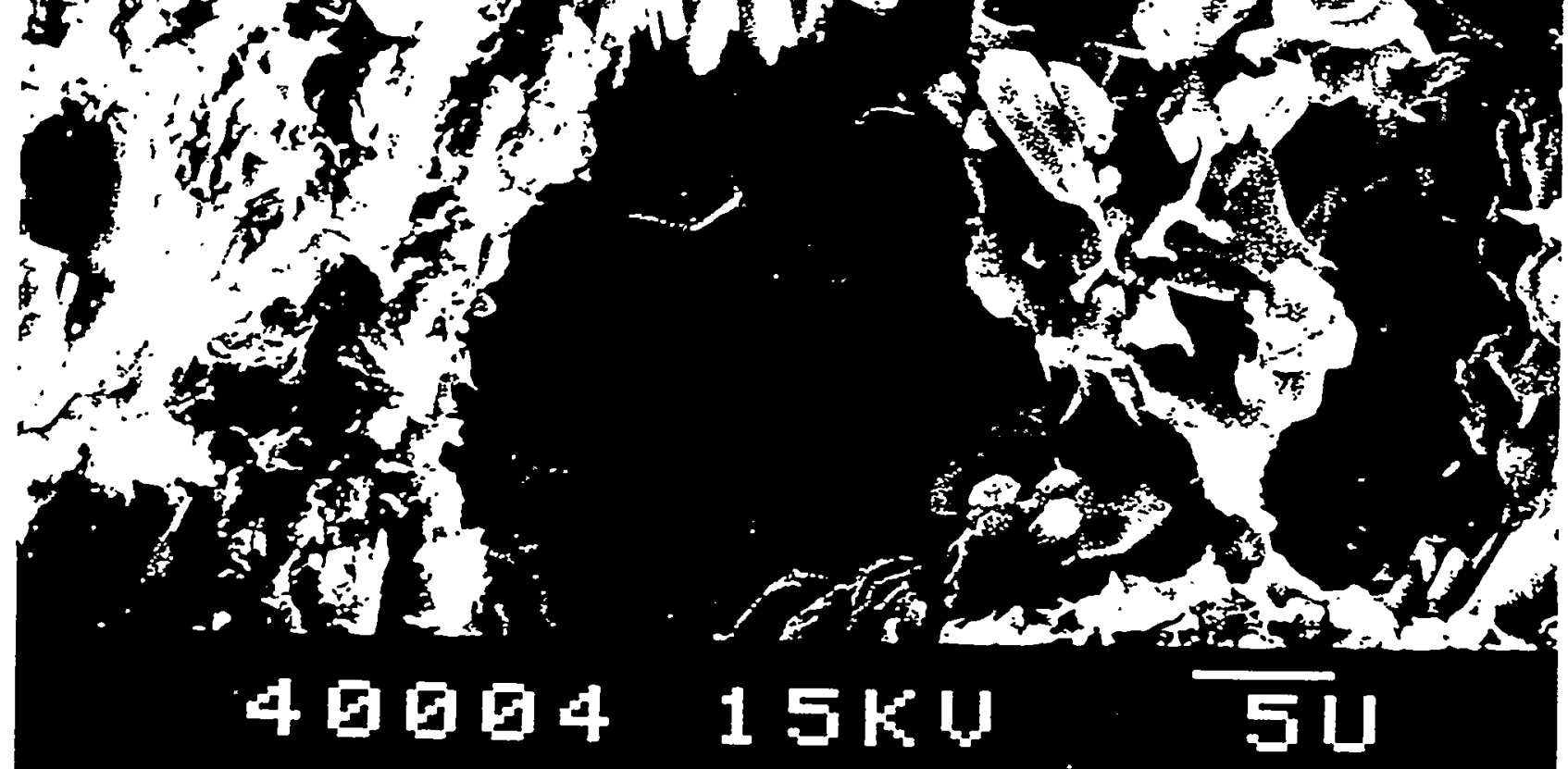




\section{CCM-1 $1141.5 \mathrm{ft} \quad \mathrm{K}=1.5 \times 10^{-12} \mathrm{~cm} / \mathrm{s}$}

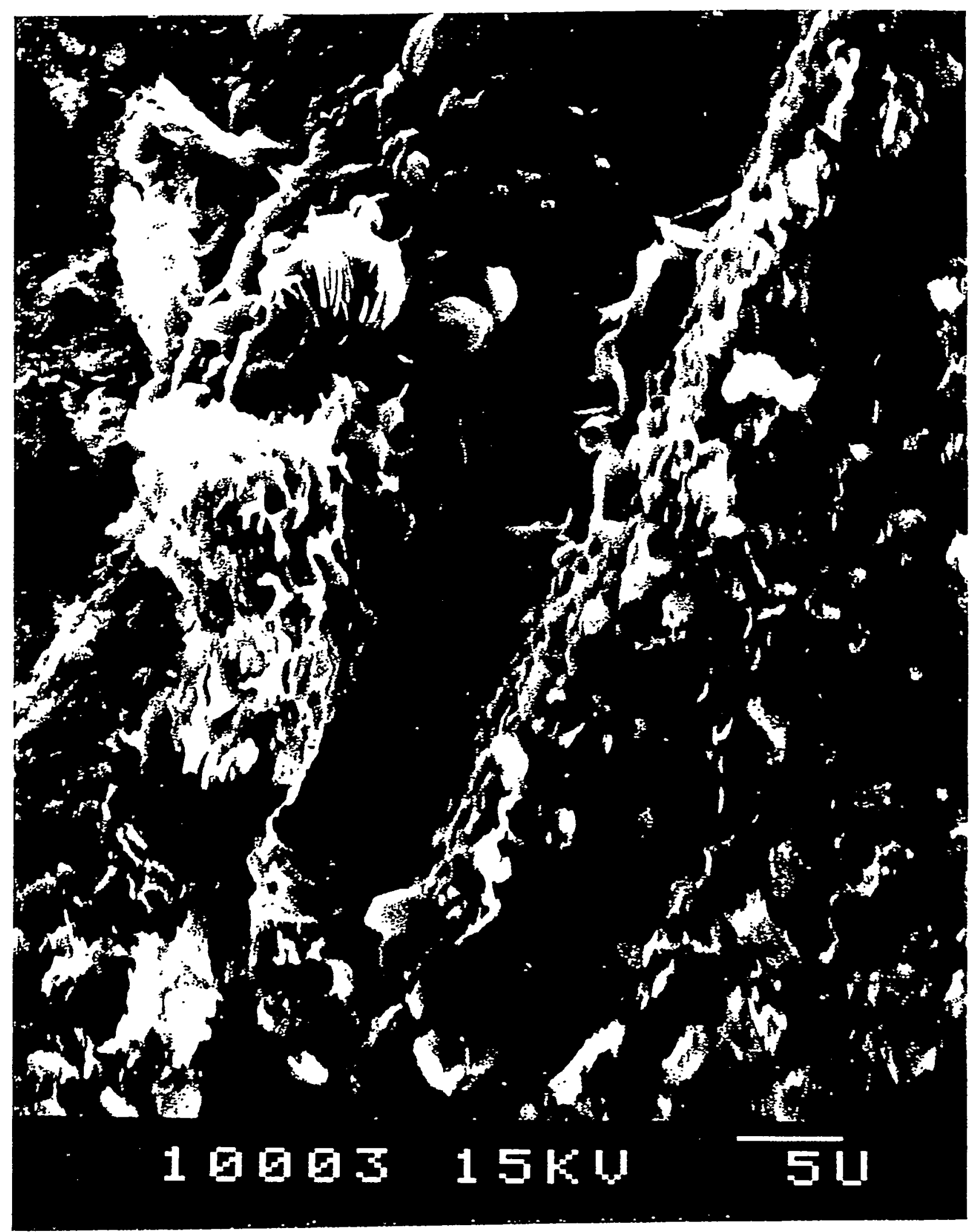




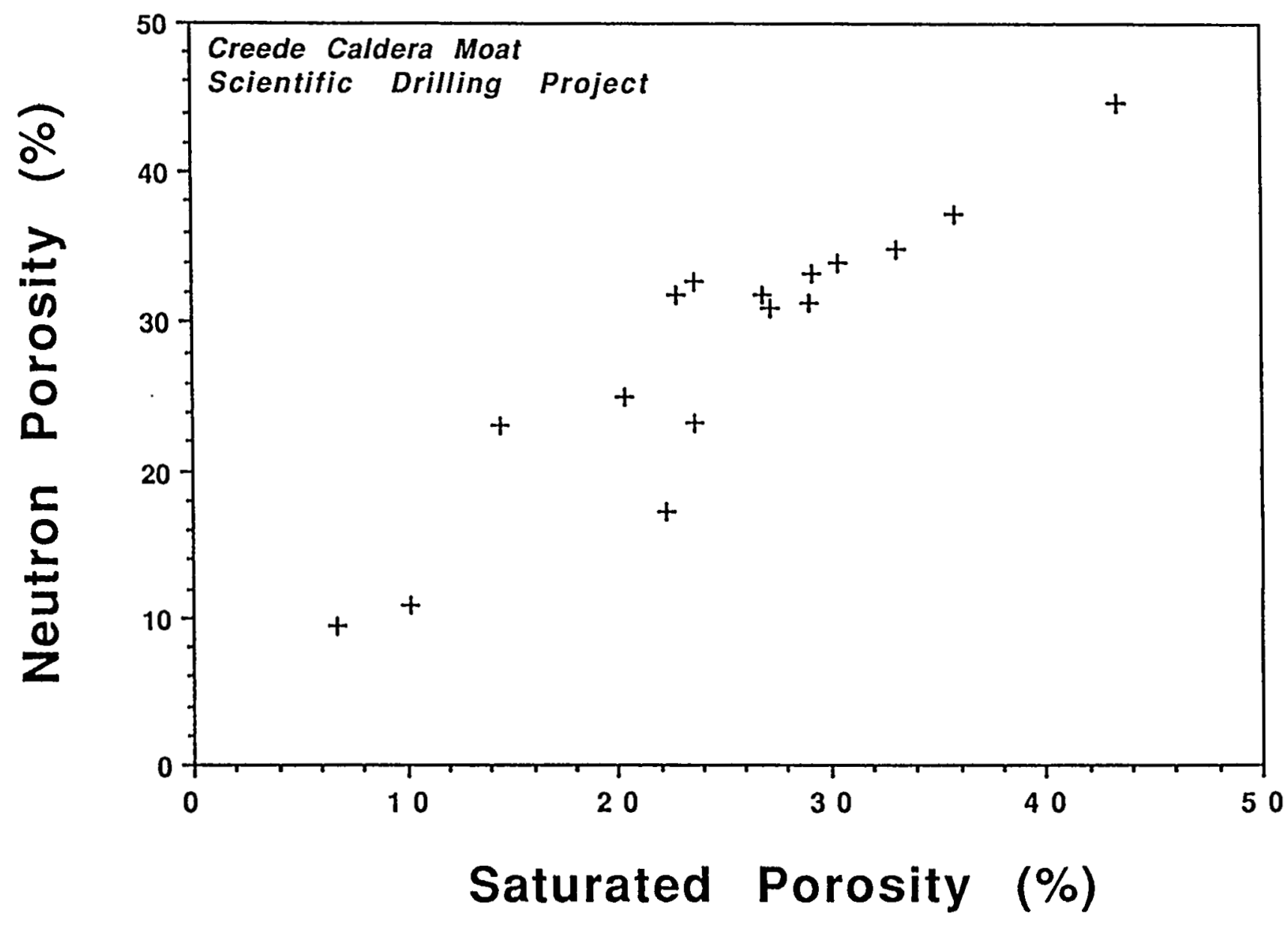

